\title{
Evaluation of Culture Conditions for Allura Red degradation by Pleurotus ostreatus under Solid State Fermentation
}

\author{
Felipe Mejía $^{1}$, Ana Cristina Jaramillo², Angelina Hormaza ${ }^{1}$ \\ ${ }^{1}$ Universidad Nacional de Colombia, Faculty of Sciences \\ St. 59a \# 63-20, Medellín, Colombia \\ fmejiao@unal.edu.co; ahormaza@unal.edu.co \\ ${ }^{2}$ University of Technology Sydney, Faculty of Sciences \\ Broadway NSW 2007, Sydney, Australia \\ anacristina.jaramillomadrid@student.uts.edu.au
}

\begin{abstract}
A huge number of pollutants are being released into the aquatic environment. These toxic compounds did not have, neither environmental friendly methodologies nor efficient politics, for their management and treatment. For instance, synthetic dyes are mostly used in the textile and food industries generating large volumes of coloured effluents. Particularly, Allura Red is an azo dye, widely used in several dyeing processes. The combined methodology, which includes adsorption onto agro-industrial wastes, and solid state fermentation with white rot fungi, has been implemented as a promising alternative for treating this kind of contaminants. In this work, it was determined the best conditions for Allura Red degradation throughout a full $2^{3}$ factorial design under solid state fermentation. The process was carried out during 20 days at $25^{\circ} \mathrm{C}$ using Pleurotus ostreatus. The highest degradation percentage of $92,7 \%$ was achieved under a Carbon: Nitrogen ratio of 20:1, a moisture content of $80 \%$ and without CuSO4 as inductor. These results suggest that the applied integrated methodology is a suitable strategy for the bioremediation of contaminated effluents.
\end{abstract}

Keywords: Azo dyes; Corncob; White rot fungi; Statistical design; Bioremediation

\section{Introduction}

Synthetic dyes are the most common compounds to give colour to a desire object. Therefore, they are extensively used in pharmaceutical, cosmetics, food and textile industries. It is believed that are more than $10^{5}$ different dyes, which are approximately produced $7 \times 10^{5}$ tons every year. Moreover, the dyeing process is not totally effective, due to a $20 \%$ of these molecules are discharged into water effluents [1], [2]. Azo dyes are characterized for having a complex chemical structure, that makes its degradation and treatment a difficult challenge [3]. Allura red, AR, is an Azo dye widely used in beverages, bakery products, dessert powders, candies, cereals, foods, drugs, and cosmetics [4]. Nevertheless, it is reported that high concentrations of this pollutant in the diet could have toxic effects [1]. Furthermore, the released of huge quantities of AR in water bodies could lead to a decreasing of light permeability, causing harmful effects on the aquatic biota [5].

Different techniques arose for the treatment of this environmental problem, that includes chemical, physical and biological technologies. The physicochemical are the most commonly used methods, such as coagulation, oxidation, photocatalytic decolourization and adsorption, on organic and inorganic supports. Most of these methodologies are expensive and could generate big amount of other wastes as well as the generation of higher toxic compounds [2]. As an alternative, adsorption of dyes onto agricultural by-products is a low cost and feasible method, because it retains the molecule without breaking it and offers removal percentages up to $90 \%$ [6].

In the same way, it has been reported several biological methods for the treatment of contamination with dyes. Solid State Fermentation, SSF, is a bioprocess that works at low moisture contents and presents several advantages in comparison with submerged fermentation, for instance the use of agro-industrial wastes as a natural substrate [7]. Additionally, the most commonly used microorganisms in SSF for the treatment of dyes are White Rot Fungi, WRF, that are characterized by their broad ligninolytic enzyme machinery [8]. Furthermore, the use of agricultural wastes, provides the natural growth environment for the WFR. 
In our research group, the combined methodology, that involves adsorption of dyes onto agricultural wastes and the subsequent degradation by WRF under SSF conditions, has been developed and has delineated a suitable strategy for the integral treatment of this kind of pollutants. In this context, the aim of this work was to determine the best culture conditions for the degradation of AR dye adsorbed onto corncob by the WRF Pleurotus ostreatus growing under SSF.

\section{Materials and Methods}

\subsection{Adsorption and Desorption.}

Corncob waste was pre-treated with processes of washing, grinding and sieving. The batch adsorption process was carried out under the optimal conditions reported in preliminary studies [9]. At the end of the fermentation, $34 \mathrm{~mL}$ of a $0.01 \mathrm{M} \mathrm{KOH}$ solution was added to the flaks and then put on agitation to remove the residual dye after fermentation. The measurement of dye concentrations was throughout a spectrophotometric method in a spectrophotometer Perkin Elmer UV-Vis Lambda 35, at maximum absorption wavelength $502 \mathrm{~nm}$.

\subsection{Fungal Strain and Culture Conditions}

The fungal strain, P. ostreatus, was kept on potato dextrose agar, PDA, plates at $4{ }^{\circ} \mathrm{C}$ and subcultured every 30 days. The SSF was carried out in $50 \mathrm{~mL}$ Erlenmeyer flasks containing $500 \mathrm{mg}$ of coloured corncob. Each flask was inoculated with two plugs of $1.0 \mathrm{~cm}$ of diameter, from an actively area of fungus growing on wheat bran agar. To adjust the C:N ratio to 20,30 and 40 , it was added $1.0 \mathrm{~mL}$ of $53.6 \mathrm{~g} / \mathrm{L}, 28.3 \mathrm{~g} / \mathrm{L}$ and $15.6 \mathrm{~g} / \mathrm{L}$ of yeast extract solutions respectively. Similarly, to reach a moisture contents of $70 \%, 75 \%$ and $80 \%$, it was added $0.2 \mathrm{~mL}, 0.4 \mathrm{~mL}$ and $0.5 \mathrm{~mL}$ of malt extract solution with the following concentrations $10 \mathrm{~g} / \mathrm{L}, 5 \mathrm{~g} / \mathrm{L}$ and $4 \mathrm{~g} / \mathrm{L}$ respectively.

\subsection{Full Factorial Design}

The moisture content, $\mathrm{C}: \mathrm{N}$ ratio and the presence of inductor $(\mathrm{CuSO} 4)$ were evaluated through a $2^{3}$ full factorial design with a central point, using the free software Statgraphics Centurion XV.II, version 16.1.18. The factors and their levels are described in table 1.

Table 1: $2^{3}$ full factorial design factors.

\begin{tabular}{|c|c|c|c|}
\hline & Low & Middle & High \\
\hline $\mathrm{CuSO} 4\left(\mathrm{mgL}^{-1}\right)$ & 0 & 0.5 & 1.0 \\
\hline $\mathrm{C}: \mathrm{N}$ & 20 & 30 & 40 \\
\hline$\% \mathrm{H}$ & 70 & 75 & 80 \\
\hline
\end{tabular}

\section{Results and Discussion}

The P-value of the F-test is less than 0.05 and according to a simple ANOVA test, the average of the $\% \mathrm{D}$ between treatments shows a significant statistical difference among them with a confidence level of $95,0 \%$. The used method to discriminate between the means was the Fisher's least significant difference (LDS), with a confidence level of $95 \%$. Thus, the multiple ranges test identified five homogenous groups; it does not exist significant statistical difference between the treatments that belongs to the same group (indicated with the same alphabetic subscript).

The evaluated treatments for the degradation of AR by P. ostreatus and the average degradation percentages obtained for each one of them are shown in table 2 .

In figure 1, it is presented the Pareto chart, indicating how much, the individual factors and the interactions between them, affect the response variable $\% \mathrm{D}$.

It should be noted that the addition of $\mathrm{CuSO} 4$, at the evaluated concentrations, does not show an inductor effect on the degradation of AR. Then, the treatments 1 and 5 belong to the same homogenous group, which point out that the variation of the degradation percentages among them is the addition of inductor. This characteristic is also displayed on treatments 3 and 7. These results contrast with the previously reported studies, which show that CuSO4 concentrations of $1 \mathrm{mM}$ increases the enzymatic activity until 8 times, in comparison with a medium without the presence of inductor [10]. 
Table 2: Degradation percentage of AR by Pleurotus ostreatus under SSF.

\begin{tabular}{|c|c|c|c|c|}
\hline Treatment & $\begin{array}{c}\text { Inductor } \\
\text { Concentration }\end{array}$ & $\begin{array}{c}\text { Moisture } \\
\text { Content }(\%)\end{array}$ & C: N & \% Degradation \\
\hline 1 & 0 & 70 & 20 & $88,3_{\mathrm{a}}$ \\
\hline 2 & 0 & 80 & 20 & $92,7_{\mathrm{b}}$ \\
\hline 3 & 0 & 70 & 40 & $64,8_{\mathrm{c}}$ \\
\hline 4 & 0 & 80 & 40 & $89,3_{\mathrm{a}}$ \\
\hline 5 & 1 & 70 & 20 & $90,1_{\mathrm{b}}$ \\
\hline 6 & 1 & 80 & 20 & $89,3_{\mathrm{a}}$ \\
\hline 7 & 1 & 70 & 40 & $67,3_{\mathrm{c}}$ \\
\hline 8 & 1 & 80 & 40 & $80,0_{\mathrm{d}}$ \\
\hline 9 & 0.5 & 75 & 30 & $75,0_{\mathrm{e}}$ \\
\hline
\end{tabular}

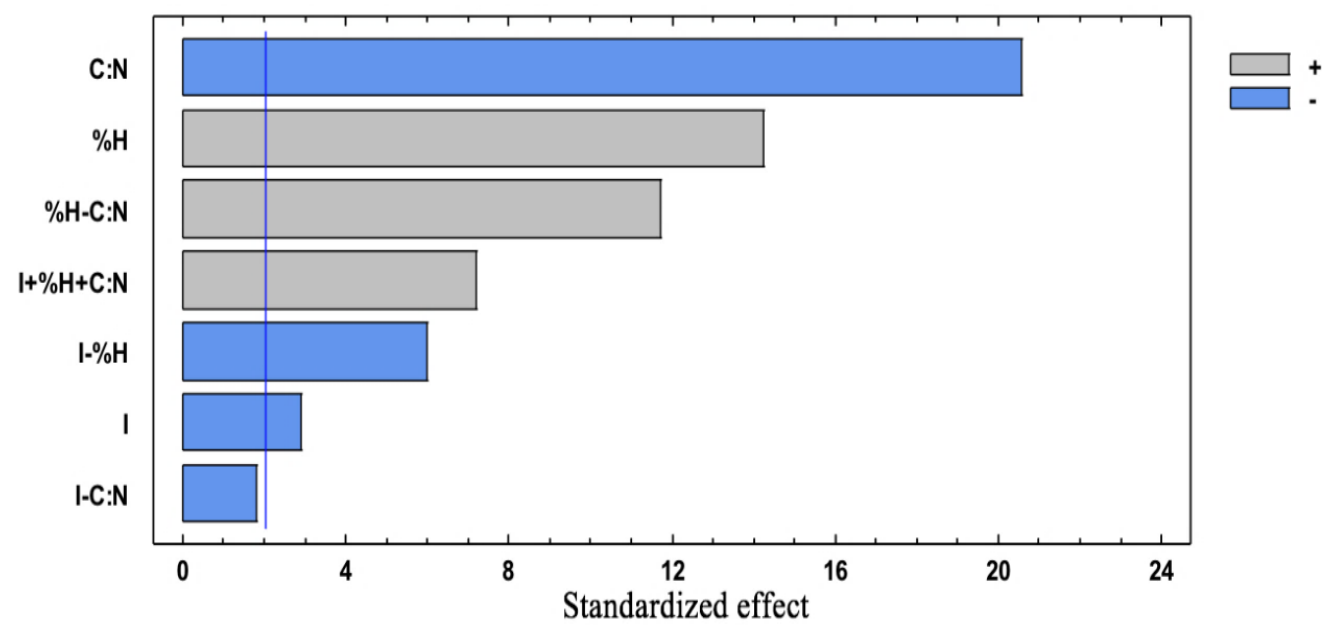

Fig. 1: Pareto chart of the degradation percentages of AR by P. ostreatus.

Furthermore, other works have reported that PoSI activity, which is an extracellular protease that degrades laccase, decrease a $77 \%$ in presence of $1 \mathrm{mM}$ of inductor [11]. Notwithstanding, there are researches that obtained an induction of the laccase by low CuSO4 concentrations $(0.1$ and $0.2 \mathrm{mM})$ using P. ostreatus, these conditions were not evaluated in this work [12].

For experiments from 1 to 4 it was found that treatments with less $\mathrm{C}$ : $\mathrm{N}$ ratio $(1,2)$ enhanced the AR degradation, which was also observed for treatments 5 and 6 with addition of inductor. Relative to the moisture content, if treatments with the highest $\mathrm{C}: \mathrm{N}$ ratio are compared, a positive effect of this factor could be observed in the percentage degradation of AR dye. This tendency was observed both in the presence and in absence of the inductor.

\section{Conclusion}

The best degradation percentage of $92.7 \%$ was reached at a C: $\mathrm{N}$ ratio of $20: 1$, a moisture content of $80 \%$ and without the presence of inductor, which shows that SSF is a highly efficient biological method for bioremediation of synthetic dyes. Moreover, these results suggest that the combined methodology, Adsorption - SSF, is an innovative strategy for treating coloured effluents. Thus, further studies are required in this field in order to scale-up the process.

\section{Acknowledgements}

The authors gratefully acknowledge Universidad Nacional de Colombia - Sede Medellín for its support through the infrastructure of the Experimental Chemistry Laboratory as well as the funding of COLCIENCIAS through the call 745 , Project Code 111871250685. 


\section{References}

[1] A. Gürses, M. Açıkyıldız, K. Güneş, and M. S. Gürses, "Dyes and Pigments: Their Structure and Properties," in Dyes and Pigments, S. K. Sharma, Ed. Jaipur, India: SpringerBriefs in Molecular Science, 2016.

[2] E. Forgacs, T. Cserháti, and G. Oros, "Removal of synthetic dyes from wastewaters: A review," Environ. Int., vol. 30, pp. 953-971, 2004.

[3] A. Gürses, M. Açıkyıldı, K. Güneş, and M. S. Gürses, "Classification of Dye and Pigments," in Dyes and Pigments, S. K. Sharma, Ed. Jaipur, India: SpringerBriefs in Molecular Science, 2016.

[4] S. Kobylewski and M. F. Jacobson, Food Dyes A Rainbow of Risks. Center for Science in the Public Interest, 2010.

[5] A. Gürses, M. Açıkyıldız, K. Güneş, and M. S. Gürses, "Colorants in Health and Environmental Aspects," in Dyes and Pigments, S. K. Sharma, Ed. Jaipur, India: SpringerBriefs in Molecular Science, 2016.

[6] A. M. Echavarria-Alvarez and A. Hormaza-Anaguano, "Flower wastes as a low-cost adsorbent for the removal of acid blue 9," Dye. Pigment., vol. 81, no. 185, pp. 131-137, 2014.

[7] C. Krishna, "Solid-state fermentation systems-an overview," Crit. Rev. Biotechnol., vol. 25, no. 1-2, pp. 1-30, 2008.

[8] D. Wesenberg, I. Kyriakides, and S. N. Agathos, "White-rot fungi and their enzymes for the treatment of industrial dye effluents," Biotechnol. Adv., vol. 22, pp. 161-187, 2003.

[9] A. Moreno, D. Figueroa, and A. Hormaza, "Diseño estadístico para la remoción eficiente del colorante rojo 40 sobre tusa de maíz," Prod. + Limpia, vol. 7, no. 2, pp. 9-19, 2012.

[10] P. Baldrian and J. Gabriel, "Copper and cadmium increase laccase activity in Pleurotus ostreatus," FEMS Microbiol. Lett., vol. 206, no. 1, pp. 69-74, 2002.

[11] G. Palmieri, C. Bianco, G. Cennamo, P. Giardina, G. Marino, M. Monti, G. Sannia, F. Ii, C. Universitario, and M. S. Angelo, "Purification, Characterization, and Functional Role of a Novel Extracellular Protease from Pleurotus ostreatus," Society, vol. 67, pp. 2754-2759, 2001.

[12] G. Palmieri, P. Giardina, C. Bianco, G. Sannia, "Copper Induction of Laccase Isoenzymes in the Ligninolytic Fungus Pleurotus ostreatus,” Appl. Environ. Microbiol., vol. 66, no. 3, pp. 920-924, 2000. 